\title{
Schopenhauer and the Objectivity of Art
}

\section{Bart Vandenabeele}

“He who has beheld beauty with his eyes,

Is already in thrall to death."

August, Graf von Platen-Hallermund

Although many people would surely agree that art stretches and extends the ways we come to see the world, enhances our understanding and enriches our mental life, few would probably claim that art provides us with objective knowledge of the world. Objectivity, we hold, cannot be obtained by creating or admiring novels, sonnets, string quartets and films. Although these will not always simply be expressions of romantic souls, their common purpose is to offer rewarding experiences. And if they do afford us some kind of knowledge or understanding, it will always be mediated by the artist's subjective view of the world. In this, artworks radically differ from scientific theories, which aim to show the true objective nature of things: whereas artists create merely subjective views of the world, scientists (or so common opinion holds) are able to offer theories, laws, hypotheses and solutions to problems that really concern the objective nature of the world, are based on a careful examination of the "facts" and are clearly more objective than the understanding that artworks may provide. It would be hard to convince anyone of the idea that, say, Giorgione's painting The Tempest is more objective than Einstein's special theory of relativity.

Yet in Schopenhauer's view, science is a subjectively coloured enterprise that merely offers knowledge that is in the service of our human desires, needs and interests. Scientific knowledge, he says, is knowledge that is dependent upon the principle of sufficient reason, i.e., it consists of solutions to problems in terms of 
causes, grounds and reasons. Scientific knowledge is the most powerful instrument we possess to subjugate the world to our human categories and concepts, and enable us to manipulate nature to a tremendously great extent. In this sense, Schopenhauer claims, science is as subjective as can be, for it is in the service of the human desire to understand and rule the world, the need to gain insight into the "deep structure" of reality, in order to help human beings feel more comfortable in nature, to survive in it and ultimately become master of it. Thus, instead of providing disinterested theories, scientists generate solutions that are in the service of the human will to survive in nature and dominate the world.

\section{Will-lessness, Science, and Art}

On Schopenhauer's view, the artist - and not the scientist - provides objective knowledge. Whereas scientists offer us mere subjective (i.e. will-driven) solutions to human problems, artists create works that are the result of will-less (i.e. disinterested) perception. Artists, Schopenhauer argues, are not (primarily) interested in expressing personal emotions. Artists offer no "human all-too-human" understanding of the world but want to take us beyond the narrow, human standpoint and no longer show the world through a human gaze; they rather provide, as it were, "a view from nowhere", a perspective on things which is no longer dominated by individual interests and desires but instead considers the world from an impersonal, de-individualised viewpoint. Scientists, Schopenhauer holds, manipulate nature in order to serve human urges and interests, whereas artists do not. Artists create works that are not (necessarily) useful for human purposes. Scientific knowledge is a way to come to terms with inhuman nature and manipulate it in order to render it less inhuman, whereas artists try to show things as they are "in themselves", i.e. as they are before 
they are captured in and through human categories and concepts. Art shows the things in their nakedness, stripped from their human meanings, categories, emotions and interests and offers us their universal essences. Artists are no longer bearers of messages or vehicles of emotions. Even music - Schopenhauer's favourite art form never expresses particular emotions, but "only the inner nature, the in-itself" of emotions, and "does not express this or that particular and definite pleasure, this or that affliction, pain, sorrow, horror, gaiety, merriment, or peace of mind, but joy, pain, sorrow, horror, gaiety, merriment, peace of mind themselves, to a certain extent in the abstract, their essential nature, without any accessories, and so also without the motives for them" (WWR I,261). In other words, music expresses, we could say, what is unemotional about emotions. The purpose of music is neither the expression nor the arousal of human emotions, but offers bare-stripped, purified, universal and dehumanised emotions, or (as Schopenhauer further puts it) "as it were the innermost soul of the phenomenon without the body", but "united with thorough and unmistakable distinctness" (WWR I, 262). No wonder so many artworks have an alienating effect, for they show us not the world as we are used to perceiving it, i.e. a world full of recognisable human characteristics, categories and conceptions that make us feel at ease and enable us to cope with the things around us. On the contrary, artworks radically disturb this confident picture and enable us to enter a world of inhuman forces.

Whereas scientific investigation is, according to Schopenhauer, merely a kind of systematic extension of our ordinary way of treating objects by which we manipulate and subject things to our human standpoint, aesthetic and artistic treatments of things offer us the most objective perception of the world. By introducing the notion of objectivity into the realm of aesthetics and art, 
Schopenhauer sets out to synthesise two radically different views on disinterested knowledge and perception, namely Plato's and Kant's. In Schopenhauer's view, these are perfectly compatible and, moreover, one could even say that his whole philosophy is - as can be gathered from the earliest manuscript remains - an (not always successful) effort to combine Platonic and Kantian insights. His emphasis on the disinterested, objective nature of aesthetic perception is perhaps the most emphatic instance of this complicated enterprise.

There are different ways to observe, perceive and study the world around us: usually we consider it from the perspective of willing individuals. But Schopenhauer believes that a totally different perspective on things is possible: the standpoint of pure will-less subjects of knowledge (which is, as we shall see, no longer really a "standpoint", for it is a view from nowhere, a perspective of a subject no longer governed by an ego). As human beings, Schopenhauer says (following Hume), we are no mere "angel heads" but embodied creatures with passions, desires, wishes, interests and affects, and our way of observing the objects around us is inevitably coloured and even determined by those subjective, personal, or individual desires and affects. Due to our nature as willing embodied beings, our perception of the world cannot be neutral, disinterested or purely objective: we ordinarily subject it to our personal point of view, and how we see things is always connected with our individual interests, desires and affects - our perception of things is a way of manipulating them, subjecting them to our personal perspective and interests, and making them useful to us. This seems to be the only possible way of considering things and perceiving the world, for if Schopenhauer is right that we are fundamentally willing beings, then our perception is inevitably influenced and even 
determined by our nature as embodied creatures and our individual affects, interests and desires.

\section{Art, Objectivity, and Death}

The only way to escape this "interested", typically human, manipulative way of considering things seems to be not considering them at all: the only way to be able to overcome our personal, willing and hence "interested" connection with the world is by giving up each and every connection with it, and ultimately giving up considering things altogether. This is actually a possibility which Schopenhauer takes into consideration seriously, and in his ethics he characterises suicide and asceticism as attempts to overcome our "interested" relationship with the world. In a way, Schopenhauer's analysis of human beings as willing creatures does seem to have the radical consequence that pure will-less objectivity can be attained only if we are no longer there: i.e. if our existence as living, willing individuals has vanished, hence (or so it seems at first sight) only when we are dead. Only then the primordial unity of everything, i.e. the metaphysical unity of the will, will have been restored: our death guarantees, as it were, that the deceptive individual perspective has been abolished completely and reveals the ultimate Schopenhauerian truth, viz. that all is ultimately one and the same thing-in-itself, i.e. one cosmic will: by dying, our individuality will be fully and permanently absorbed into the cosmic will. So, as Nietzsche will not hesitate to emphasise, Schopenhauer's view of the metaphysical nature of the world as will, the willing and interested nature of human perception and the idea that the individual can only find eternal peace by disappearing as individual, i.e. by passing away, offers no way out of the predicament of either the misery and suffering of individual subjectivity or the eternal peaceful darkness of death or nothingness. 
Fortunately, however, Schopenhauer sees a way out of this predicament and sketches a fascinating alternative to both death and "merely subjective" perception. Although the whole world, including human life, is nothing but an uncanny puppet show of one and the same blind and ruthless will, one does not have to give up considering things altogether to be able to attain a state of pure, will-less, and painless perception or intuition (Anschauung). For, during a few scarce moments in our lives, all of a sudden

we enter the state of pure contemplation, we are raised for the moment above all willing, above all desires and cares; we are, so to speak, rid of ourselves. We are no longer the individual that knows in the interest of its constant willing; the correlative of the particular thing to which objects become motives, but the eternal subject of knowing purified of the will, the correlative of the Idea. And we know that these moments, when, delivered from the fierce pressure of the will, we emerge, as it were, from the heavy atmosphere of the earth, are the most blissful that we experience. (WWR I, 390)

Instead of the complete objectivity of death, Schopenhauer here characterises a peculiar state of consciousness, in which we are still live subjects and yet become aware of ourselves as pure, will-less subjects of knowledge, who have overcome the ordinary state of the willing individuals that we usually are. In this state of pure contemplation, we are raised "above all willing, above all desires and cares", and are able to experience what it is to be overwhelmed by the perception of an object. This state of pure contemplation (in which we become one with the object we perceive) is, Schopenhauer argues, aesthetic. For it is what happens when a natural object or an 
art work fascinates us in such a way that our sensory experience of it is no longer driven by human needs, interests, and affects. Our ordinary empirical consciousness of the object, which is determined by the subjective forms of space, time and causality, has been suspended and replaced by a pure aesthetic way of perceiving. We are fully absorbed in the object and lose ourselves in the contemplation of it:

When, however, an external cause or inward disposition suddenly raises us out of the endless stream of willing, and snatches knowledge from the thraldom of the will, the attention is now no longer directed to the motives of willing, but comprehends things free from their relation to the will. Thus it considers things without interest, without subjectivity, purely objectively; it is entirely given up to them in so far as they are merely representations, and not motives. Then all at once the peace, always sought but always escaping us on that first path of willing, comes to us of its own accord, and all is well with us (uns its völlig woh). (WWR I, 196; italics added)

It will perhaps be hard to find a more intense and elated characterisation of the pleasure and even happiness inherent in aesthetic experience. Although one can hardly deny the enthusiasm of Schopenhauer's characterisation of aesthetic experience, it is nonetheless clear that his description will definitely apply only to some aesthetic experiences and does not cover the whole range of the kinds of experiences that are commonly characterised as aesthetic.

The passionate way in which Schopenhauer describes the aesthetic experience cannot be based on mere personal experience, but ought to be situated in the context of his basically pessimistic view of man and world. From his youth onwards, 
Schopenhauer had been looking for a way of approaching the world that could - at least momentarily - offer a way out of the thraldom of the will and the suffering that is inextricably linked up with it. In 1812, when he was still in Berlin, he already seems to have identified the experience of aesthetic pleasure as the ideal way to escape from the misery of ordinary empirical consciousness of the world, which is full of horror and suffering, and enter into the blissful state of what he then still called the better consciousness. Ordinary consciousness is embodied, and connected with individual interests and desires, and since those can only be momentarily satisfied and will constantly be replaced by new ones, they inevitably lead to the pain of unfulfilled desire. The better consciousness, however, is consciousness of oneself as pure willless, timeless, and painless subject of knowledge. It is an "experience" of being purified of one's own human individuality - which is not really an experience in the usual sense, for (strictly speaking) there is no individual being to experience this, but only a pure, de-individualised mental state and impersonal "vanishing point", a "clear mirror of the object", an imperceptible perceiver; pure awareness of harmony, tranquillity and even, Schopenhauer insists, "unearthly serenity" (WWR II, 380). Here we find the clearest instance of Schopenhauer's fascinating blending of Platonism and Buddhism: in a crucial chapter on genius and artistic creativity, Schopenhauer even calls this mental state:

the hour of inspiration, the moment of rapture or exaltation (...) the intellect's becoming free, when, relieved for a while from its service under the will, it does not sink into inactivity or apathy, but is active for a short time, entirely alone and of its own accord. The intellect is then of the greatest purity, and becomes the clear mirror of the world... (WWR II, 380) 
What Schopenhauer describes here is a complex state of mind which is completely purified of emotion, desire, needs and interests, but is by no means passive or apathetic. It creates a radical rupture with ordinary empirical consciousness, which is naturally in the service of our individual needs, urges and affects, and is - in a way more passive, for it is a mere physiological reaction of our will to the environment. Certain experiences, Schopenhauer argues, are so intense that they are able to lift us above ourselves and enable us to get rid of all the excessive lumber of individual emotions, desires and even thoughts. Our individuality has vanished and all that is left is a state of de-individualised, "pure" subjectivity which is no longer determined by the urges of individual willing.

Beauty thus rests on this disinterested objectivity of perception. Schopenhauer even claims that "everything is beautiful only so long as it does not concern us" (WWR II, 374). The drastic nature of this definition cannot be sufficiently stressed. All typically human, individual ways of considering an object are suspended and what remains is a subject without ego, which perceives the aesthetic object emotionless, thoughtless - we come to see the world "from outside" (WWR I, 372). Schopenhauer's characterisation of beauty is, to say the least, unusual. An experience of beauty is, in his terms, abnormal: a purely disinterested, will-less and detached (but also, paradoxically, unusually intense and focussed) state of consciousness, in which we have transcended our individual interests, and have ultimately become the object's "pure mirror" (WWR II, 367). We have become somehow disengaged and even estranged from the world, for we have adopted a stance in which "the entire consciousness is filled and occupied by a single image of perception" (WWR I, 179). 
This "abnormal" aesthetic state of mind cannot proceed from a conscious act of will (Akt der Willkür): we cannot decide to enter into the blessed state of the better consciousness but will always be stimulated by an object that we are fascinated by and through which we can enter into a peaceful, timeless and tranquil state of mind:

The change in the subject required for this, just because it consists in the elimination of all willing, cannot proceed from the will, and hence cannot be an arbitrary act of will, in other words, cannot rest with us. (...) Such a state of itself eliminates the will from consciousness, and in it all things stand before us with enhanced clearness and distinctness, so that we are aware almost alone of them and hardly at all of ourselves. Therefore our whole consciousness is hardly anything more than the medium through which the perceived object appears in the world as representation. Thus pure will-less knowledge is reached by the consciousness of other things being raised to so high a potential that the consciousness of our own selves vanishes. For we apprehend the world purely objectively, only when we no longer know that we belong to it; and all things appear the more beautiful, the more we are conscious merely of them, and the less we are conscious of ourselves. (WWR II, 367-368)

This passage reveals how far removed Schopenhauer's theory of aesthetic perception is from Kant's analysis of aesthetic judgment. Although Schopenhauer's will-lessness clearly echoes Kant's concept of disinterestedness, Schopenhauer radically breaks with the idea that aesthetic experience is based on the reflection and feeling of a judging subject. Schopenhauer's aesthetic subject is a subject in which the capacity to judge - not only of determining but also of reflecting judgment - has 
vanished altogether. Schopenhauer's pure aesthetic subject does not judge, it is not detached in the sense that it takes some distance to be able to judge the object; it is, on the contrary, totally swallowed and taken in by the object. It does not behave as someone who, after many years, meets an old friend again and studies her features to see whether she has changed much, but as a passionate lover who is so madly in love that he forgets everything, even himself, and melts together with the other and becomes one with her. And perhaps even this comparison is not really accurate enough, since Schopenhauer warns us against too romantic an identification of aesthetic beauty with amorous passion (WWR II, 374): despite his use of terms such as rapture, exaltation and enjoyment, the type of awareness he describes, makes clear that an aesthetic experience is not so much a matter of emotions, affects or feelings, but of inner peace, serenity, complete objectivity and painless contemplation; willing is expelled from consciousness.

In this sense, his account is clearly reminiscent of Plato's pure knowledge of the soul. For Plato, however, an experience of beauty is a festive celebration of Being: it is (as in Kant) to feel alive. On Schopenhauer's account, though, having an aesthetic experience is an intimation of death: the world has become "something foreign" to us (WWR II, 387), for we are pure detached subjects that have become one with the object of our perception. We lose ourselves and "become the pure mirror of the objective inner nature of things" (WWR II, 367); "we have stepped into another world (...) where everything that moves our will (...) no longer exists" (WWR I, 197), and are aware only of the deprivation of everything that is typical of individual human being (see WWR I, 178; I, 195-6). We have become will-less, timeless, and totally disengaged subjects - subjects without ego; so hardly subjects at all, since we remain "wholly foreign to, and detached from, the scene to be contemplated", and 
adopt "the view from nowhere" (WWR II, 373; see Nagel 1986). We have become so overwhelmed by the perception of the object, that we are no longer conscious of our individual selves anymore, and have temporarily become disposed of our own living nature, our own will to life (lbid.).

Aesthetic consciousness is not merely an escape from the torments of our existence as willing subjects, though, but also offers us understanding and knowledge. A peculiar type of knowledge, however: not based on (determinate) concepts, as is the case in the "subjective" kind of knowledge that is scientific knowledge, for instance, but knowledge of, what Schopenhauer calls, (Platonic) Ideas.

3. Objective Knowledge of (Platonic) Ideas As noted above, Schopenhauer was always fascinated by the possibility of a "better consciousness", not only as a kind of awareness that enables us to escape from the sufferings that are inherent in our nature as willing individuals, but also as a path to a superior kind of knowledge and understanding which transcends the ordinary way of perceiving and coping with the world around us and our position in it (WWR I, 372; WWR II, 386).

Ordinary knowledge needs concepts to be able to understand the things around us and carve nature at its joints. In the aesthetic state of consciousness described above, however, the object is not known by means of concepts; aesthetic cognition is not characterised by the conceptual clarity and rigid distinctions typical of scientific insights, for "we are entirely satisfied by the impression of a work of art only when it leaves behind something that, in spite of all our reflection on it, we cannot bring down to the distinctness of a concept" (WWR II, 409). Although Schopenhauer 
continually identifies the Ideas as Platonic - as timeless, universal essences - this crucial observation intimates that his characterisation of artwork in terms of vehicles of knowledge and understanding that transcend our conceptual knowledge of objects is close to Kant's suggestion that works of art communicate aesthetic ideas. Aesthetic ideas, Kant says, are the products of the artist's imagination, which strives "toward something that lies beyond the bounds of experience" - or more precisely, "inner intuitions (innern Anschauungen) to which no concept can be completely adequate" (Kant, 1987, $\S 49,5: 314$ ). This is exactly the thought that we find in Schopenhauer, but it should not blind us to the important differences between their respective views: artistic imagination in Kant is "productive", for it invents intuitions and produces new configurations, whereas for Schopenhauer the Ideas are the timeless universals which the artist merely discovers by adopting an objectifying, disinterested and de-personalised stance towards the world. Nonetheless, the suggestion that art works communicate ldeas that offer a kind of understanding or knowledge that cannot be reduced to the knowledge we gain through concepts is important, for it gives the lie to those that consider aesthetic knowledge to be inferior to the (scientific and philosophical) sort of knowledge that is conceptual in nature.

Yet what kind of knowledge Schopenhauer has in mind when he characterises will-less aesthetic knowledge in terms of knowledge of timeless Ideas still remains puzzling. One commentator offers the following: "The Ideas might just be ordinary perceptual objects $(\ldots)$ their universality having to do (...) with the selectiveness of attention paid to them by the observer (...) Perceiving an Idea (...) is a matter of perceiving an ordinary object but with one's attention focussed on its essential, and away from its inessential aspects." (Young 1987, 434) What is significant in an object, though, does not necessarily coincide with the "universal" it is supposed to be an 
instance of (see Janaway 1996, 53). What is significant in an object is not necessarily something universal. In artworks minute details of brushwork, colour hues, voice timbre, etc. are often more artistically relevant and significant than the ideas conveyed. Moreover, the universal ideas that are expressed in some masterpiece painting may often be rather trivial. If the way in which the artist renders the subjectmatter does not really engage us in stimulating and moving ways and enrich our imaginative capacities, the art work will not be of much value (and will definitely not lead to the blissful state of the "better consciousness" which Schopenhauer identifies as the aesthetic attitude). Good art not only occasions interesting ideas but develops our capacities for discrimination and appreciation. The value of a work of art mainly depends on the way it penetrates and shapes our grasp of the ideas and attitudes conveyed. Art's cognitive value cannot be reduced to the ideas - Platonic or not that they express and communicate. The way in which they stimulate our imaginative perception and shape our discriminatory capacities is at least as important a value of good art as conveying crucial thoughts or ideas might be.

Schopenhauer's Platonic idealism fails to accommodate for the particularly valuable way in which art can express ideas, thoughts, emotions and attitudes. This is a fundamental value of good art, though. Take any work by such masters as Roger van der Weyden, Lorenzo Lotto, René Magritte and Alberto Giacometti, for example. The ideas they convey and themes they treat may at times be very trivial, but the value of their work does not solely (nor perhaps primarily) depend on the content of the ideas they communicate. It is the sophisticated, complex and often radical way those artists challenge, shape and transform our visual attention and imagination, using multiple revolutionary techniques and contrasting distinct detailing which renders some of their works eminent masterpieces. Schopenhauer does pay some 
attention to the exquisite way in which Dutch still-life painters manage to direct "such purely objective perception to the most insignificant objects, and set up a lasting monument of their objectivity and spiritual peace in paintings of still life", and "in the same spirit landscape painters, especially Ruysdael, have often painted extremely insignificant landscape objects, and have thus produced the same effect even more delightfully" (WWR I, 197).

Yet he seems too preoccupied with defending art against Plato's estimation of it. Plato claimed that art is worthless and even harmful, since it only offers the illusion of knowledge and leads us away from a genuine understanding of the world. Contra Plato, Schopenhauer argues that art can afford true knowledge and understanding. Now he is so eager to repudiate Plato's scathingly negative estimation of art by offering a Platonic answer himself, that he does not pay sufficient attention to the way in which art can be cognitively significant, not because it necessarily conveys universal, timeless, Platonic Ideas, but (more importantly) due to the way it shapes, expands and deepens our cognitive and imaginative capacities and enriches our mental life. The way in which such artists as Orlandus Lassus, Bach, Shakespeare, Keats, Wilde, Rothko, Pollock, Magritte, etc. have been successful in modifying the forms, styles and media through which they transmit their ideas explains the significance and timeless value of their work. Not (primarily) because they communicated universal or revolutionary ideas, but because they expressed their ideas in an absorbing, touching and enriching way, and shaped how we look at what their art expresses. Thus what matters is not primarily the nature or content of the ideas themselves, but whether the media and styles of representing or expressing them deepen our responses to them and shape and modify our grasp of the ideas conveyed - and not necessarily, as Schopenhauer would have it, how they enable us 
to adopt an objectifying, "disengaged" stance towards the miseries of the world, in which we feel no longer concerned by them.

\section{Tragic Art, Concerned Individuals, and the Objective Stance}

Although Schopenhauer emphasises the tranquil nature of aesthetic contemplation, this does not really apply to all art forms, and does not apply to the effects of tragedy at all. Whereas observing a tulip or still-life painting can definitely have a soothing effect on us, a tragedy compels us to attend to features of life we normally tend to shy away from. It makes us dwell on bloodshed, murder, and cruel violence. By foregrounding the evil aspects in particularly vivid and striking ways, it invites or even forces us to focus on the disturbing aspects of humanity, which is ultimately vicious, unjust and ugly. A tragedy confronts the spectator with, what Schopenhauer calls, "the guilt of existence itself" (WWR I, 254) and the bitterness and uselessness of life, and hence with the futility of all our individual striving. Hence, the aesthetic spectator experiences uneasiness and even disgust, for he understands "that it is better to tear his heart away from life, to turn his willing away from it, not to love the world and life", and "thus in the depth of his being the consciousness is then stirred that for a different kind of willing there must be a different kind of existence also" (WWR II, 435). Schopenhauer even writes that the best tragedies show us:

... those powers that destroy happiness and life, and in such a way that the path to them is at any moment open even to us. We see the greatest suffering brought about by entanglements whose essence could be assumed even by our own fate, and by actions that perhaps even we might be capable of committing, and so we cannot complain of injustice. Then, shuddering, we feel ourselves 
already in the midst of hell (dann fühlen wir schaudernd uns schon mitten in der Hölle). (WWR I, 255)

Tragedy not only depicts the renunciation of the will on stage, but also apparently makes the spectators shudder at the depicted horrors. The word "shuddering" (schaudernd) is especially striking here. The force of a tragedy seems to be that it truly involves an individual human being and necessitates a personal (or subjective) reaction. Without any personal involvement as a spectator, we would not be moved at all by what the characters on stage have to endure. So it is not the pure subject of knowledge, the subject without $I$, described above, which seems to be explicitly addressed by tragedy. Contrary to other forms of art, tragedies do not address detached aesthetic subjects, but concerned individuals that are able to empathise with the characters and events on stage. And while the younger Schopenhauer still thought that the renunciation of the will occurs principally in the characters of the play and not in the spectator, later (in the 1844 edition of The World as Will and Representation) he realises that forsaking our personal interests and desires necessarily presupposes the personal involvement of a willing individual. And even already in 1818 he writes the following about the effects of tragedy:

In one individual [the will] appears powerfully, in another more feebly. Here and there it reaches thoughtfulness and is softened more or less by the light of knowledge, until at last in the individual case this knowledge is purified and enhanced by suffering itself. It then reaches the point where the phenomenon, the veil of Maya, no longer deceives it. It sees through the form of the phenomenon, the principium individuationis; the egoism resting on this expires 
with it. The motives that were previously so powerful now lose their force, and instead of them, the complete knowledge of the real nature of the world, acting as a quieter of the will, produces resignation, the giving up not merely of life, but of the whole will to life itself. (WWR I, 253)

We are surprisingly far removed from a purely aesthetic experience - at least in the sense in which Schopenhauer interprets the term "aesthetic". It is therefore worth noting that in the second volume of The World as Will and Representation, published in 1844, Schopenhauer draws an analogy between the effects of tragedy and the feeling of the sublime (das Erhabene), for the tragic consists in enjoying that which "directly opposes the will" (WWR II, 433; see also Vandenabeele 2003).

Schopenhauer sets out to explain the "paradox of tragedy", which dates back to Aristotle, i.e. how we can take pleasure in horrifying events (see Vandenabeele 2007, $574-578 ; 2008,199-208)$. He attempts to do so by insisting that we comprehend the depicted events as terrible for humanity in general, and not just for our individual selves (see Alex Neill's contribution to this volume.) For Schopenhauer, tragedy stands apart from other art forms, because it does not merely offer an aesthetically rewarding experience but first and foremost yields an ethically significant insight into the true nature of man and world. It offers us a universal Idea of human existence, and thus induces a pure will-less, objective state of mind. This arguably explains our fascination for tragedies, i.e. explains why we do not merely turn away from them in utter horror and disgust.

Schopenhauer's emphasis on the objective nature of artistic knowledge shows the deep unity underlying not merely the different art forms (architecture, painting, sculpture, literature, and music too), but also of Schopenhauerian aesthetics and 
ethics as such. Although Schopenhauer clearly (and justly) distinguishes playful aesthetic appreciation from serious ethical judgment and action (WWR I, 267), he does draw interesting parallels between both, stressing their fundamental unity. Art may be merely "the camera obscura which shows the objects more purely, and enables us to survey and comprehend them better. It is the play within the play, the stage on the stage in Hamlef" (WWR I, 266-267) and the artist "bears the cost of producing that play; in other words, he himself is the will objectifying itself and remaining in constant suffering", whereas in the ethical man par excellence - "the saint who has attained resignation" - the will freely abolishes itself and the will to life is completely denied (WWR I, 285). Yet, despite the important differences between aesthetic contemplation and ethical resignation (which we cannot deal with here), it will be clear that, on Schopenhauer's view, there is a common factor that binds the two inextricably together. This common factor will again be best illustrated by focusing on tragic art.

The value of tragedy does not reside solely in aesthetic contemplation, but in understanding that it may be better to give up willing altogether. Its chief merit, Schopenhauer holds, lies in the peculiar kind of understanding it offers and the ethical stance it may henceforth provoke in a spectator. Schopenhauer has misled several commentators by concentrating on the old (Aristotelian) question of how something tragic can still offer us pleasure (see Vandenabeele 2008). But the value of tragedy does not ultimately lie in the pleasure it may yield despite its depiction of bleak and horrific contents, but in the specific ethical attitude it may generate, which is, for Schopenhauer, valuable in its own right and may lead to salvation and enlightenment through, what he calls, the complete denial of the will to life. All art and hence definitely also the highest of all the poetic arts: tragedy - merely offers a 
certain consolation that makes us momentarily forget life's appalling miseries (WWR I, 372) and yields a better understanding of the world and ourselves. At best, it awakens for a few moments the desire for "an existence of an entirely different kind, a different world" (WWR II, 433). The experience of utter horror and even disgust at the sight of the terrible events moves us personally and prompts us to turn away from the will to life, instead of remaining in peaceful contemplation of it. Thus at least part of our experience of a tragedy is therefore not pleasurable at all, but this does not make it less valuable for it, on the contrary. Tragedy is even superior to other art forms, for it makes us understand the real (limited) value of our lives as human beings and the world we live in.

Yet Schopenhauer confuses the distinction between a universal and a particular truth with the distinction between a truth that is grasped by a will-less subject and a truth that is grasped by a willing individual. A tragedy does communicate universal truths through particular events and individual characters on stage, but this does not rule out that it may also demand a spectator's personal involvement. And only because of this personal involvement can tragedy get the profound significance it really deserves. One gains some kind of understanding or knowledge from a tragedy. Again, watching a tragedy is not a purely aesthetic experience in this sense. The value of great tragedies such as Othello and Wallenstein is tightly entwined with a profound concern for the rough and brutish aspects of human nature, and does not involve merely the intellect's escaping the service of the will and operating in a disinterested way. Since what we learn from tragedies about the world and human nature is undoubtedly horrifying, it can be justified only through deliverance (Erlösung) from suffering and life, complete resignation and "denial" or abolition of the will (see WWR I, 397). 
As Schopenhauer himself recognises, the horror "is brought terribly near to us" and "shows us those powers that destroy happiness and life, and in such a way that the path to them is at any moment open even to us" (WWR I, 254-255; italics added). Experiencing tragic art really involves being confronted with horrifying truths that affect us directly as concerned individuals; truths which cannot be turned into pleasurable spectacles that can be contemplated by a detached pure subject of knowing. On the contrary, the essence of the experience of a tragedy is not that it compels us to contemplate the world but instead makes us "turn away from the will to life itself" (WWR II, 433).

"Turning away from the will to life itself" is, however, exactly the kind of transformation that - despite their obvious differences - ultimately unifies aesthetic and ethical "experience" in Schopenhauer's view. What Schopenhauer acknowledges as characteristic of both the aesthetic and the ethical attitude toward life, is the hardly expressible state of mind, which we identified above as objective. This objective state of mind, Schopenhauer insists, cannot really be positively described in philosophical terms, but "can be expressed only negatively as denial of the will" (WWR I, 410). It cannot be positively known or "experienced" - at least, not when "experience" is understood in its ordinary, "human" sense - but some people can gain access to it, often through severe discipline and heavy effort. Paradoxically enough, this state of "objective knowledge" cannot really be called knowledge anymore, since "it no longer has the form of subject and object" (WWR I, 410): it is an "experience" that "cannot be further communicated" (Ibid.) - it is, what Schopenhauer calls, knowledge sub specie aeternitatis (i.e. under the aspect of eternity).

Understanding that it may be better to turn ourselves away from this wretched world may be an important effect of, for instance, watching a tragedy, but whether 
this kind of insight really provides pleasure is highly questionable. Of course, it may provide pleasure if we have the sense that we have discovered something important about ourselves or about the world, if we understand that the work has shaped and deepened our thoughts through our experience of it. But claiming that art is valuable merely because of the pleasure this insight or understanding arouses is - to say the least - highly implausible. As Matthew Kieran says, "art stretches, extends and revolutionises the ways we come to see the world. It is one of the most powerful means of cultivating our perceptual capacities" (Kieran 2005, 147), and, we might add, of enriching our understanding of the world and ourselves.

Tragic art "furnishes us a vivid illustration of the frustration of human effort and of the vanity of this whole existence (...) and thereby reveals life's deepest meaning", Schopenhauer argues. Hence, tragedy enables us "to will something better" and escape from this dreadful life steeped in suffering, no more no less (WWR II, 635; WWR II, 574). The idea that it would be wiser to turn away from life altogether arises "only in an obscure feeling" (ibid.). It merely offers some sort of intuitive understanding that it might be better not to interfere in the "natural course of things" and instead calmly and compassionately welcome the events of life (see Cartwright's contribution to this volume).

5. The Objectivity of Art and the Abolition of the Self

Despite what some commentators suggest, Schopenhauer does not, however, expect art - not even tragic art - directly to offer resignation. The sedation and abolition of the will to life is ultimately an effect of grace: 
Now since (...) that self-elimination of the will (Selbstaufhebung des Willens) comes from knowledge, but all knowledge and insight as such are independent of free choice, that denial of willing, that entrance into freedom, is not to be forcibly arrived at by intention or design, but comes from the innermost relation of knowing and willing in man; hence, it comes suddenly, as if flying from without. Therefore, the Church calls it the effect of grace; but just as she still represents it as depending on the acceptance of grace, so too the effect of the quieter or sedative (Quietiv) is ultimately an act of the freedom of the will. In consequence of such an effect of grace, man's whole inner nature is fundamentally changed and reversed, so that he no longer wills anything of all that he previously willed so intensely; thus a new man, so to speak, actually takes the place of the old. For this reason, the Church calls this consequence of the effect of grace new birth or regeneration. For what she calls the natural man, to whom she denies all capacity for good, is that very will to life that must be denied if salvation is to be attained from an existence like ours. Behind our existence lies something that becomes accessible to us only by our shaking off the world. (WWR I, 404-405)

Thus works of art, especially those that confront us with the more tragic aspects of life, may awaken in us some kind of enlightened understanding and offer us a "new birth or regeneration" (WWR I, 404; see also WWR II, 574), although whether or not we will enter into this enlightened state, this "kingdom of grace", wherein our will to life vanishes completely and our "whole being is fundamentally changed and reversed", is not within our control: it is "the effect of grace" (WWR I, 403; I, 404). This sudden radical transformation from my life as a willing individual to a state of 
pure objectivity - for this is what Schopenhauer alludes to - is not something that I can deliberately intend or will. On the contrary, willing and striving to attain a will-less objective stance may well be the worst possible way to achieve it (see Reginster $2009,104-108)$. But aesthetic perception - which is itself more often than not a state of grace - can still be an excellent occasion to reach this blessed will-less state, which is "man's greatest prerogative" (WWR I, 404), for it saves us from the damaging influence of the will to life.

Aesthetic contemplation thus not only enables us to escape misery and boredom, but also offers us at least a fleeting glimpse of another, "objective" world, and may ultimately lead to a more permanent attainment of an ethical stance of complete resignation, which transcends the common, "natural" and egocentric attitude that we usually occupy as ordinary willing individuals (see Wicks 2008, 127$141 ; 188-190)$. The objective apprehension of the world, which we attain through aesthetic contemplation and art, may yield the insight that our individual selves may not be as important as we happen to think from our narrow, bigoted perspectives, and add to our lives the deep tranquillity, complete serenity, and inner peace that so many of us long for but never attain - governed as our lives are by the principium individuationis and the sheer torments of the will to life:

But we now turn our glance from our own needy and perplexed nature to those who have overcome the world, in whom the will, having reached complete selfknowledge, has found itself again in everything, and then freely denied itself, and who then merely wait to see the last trace of the will vanish with the body that is animated with that trace. Then, instead of the restless pressure and effort; instead of the constant transition from desire to apprehension and from 
joy to sorrow; instead of the never satisfied and never-dying hope that constitutes the life-dream of the man who wills, we see that peace that is higher than all reason, that ocean-like calmness of the spirit, that deep tranquillity, that unshakable confidence and serenity, whose mere reflection in the countenance, as depicted by Raphael and Correggio, is a complete and certain gospel. Our knowledge remains; our will has vanished. (WWR I, 411)

This passage reveals the radical nature of the transformation Schopenhauer is talking about: true knowledge, i.e. the understanding attained through the disinterested perception of aesthetic objects (and, through these, of universal Ideas), may ultimately quieten the will and bring about the abolition of nothing less than myself as such, i.e. of my "real self", for "the real self is the will to life" (WWR II, 606). When this happens, knowledge does not merely escape the service of the will, as in pure aesthetic contemplation, but leads to the complete self-suppression of the will, which characterises ethical resignation and ultimately involves the elimination of the willing self. This radical abolition of the self induces genuine peace of mind, freedom and salvation (Heil), and deliverance from suffering and, hence, from life - or "Nirvana", as the Buddhists call it (see Wicks 2008, 87-94) - beyond good and evil, since "after the arrival of the 'new birth', the morality or immorality of previous conduct becomes a matter of indifference" (WWR I, 357; II, 607; see also II, 608 ff.). This state of complete repose, which cannot be brought on by a resolve or an act of will, but "comes suddenly as if flying in from without" (WWR I, 404), is not an experience of something positive, and can only be reached by whomever has given up his "real self". Nothing positive has really been attained - apart from the fact that one has reached a state of complete objectivity and tranquillity. But this peace, 
tranquillity and genuine freedom is not human peace, tranquillity and freedom, but an inhuman empty stance, in which the illusory character of ordinary empirical knowledge has been unmasked and "the veil of Maya" has been torn to pieces; now we really know and we return, as it were, to a more "natural" and "original" unity with all that is and has been. The abolition of the will in us is at the same time the disappearance of our personal characters, our (willing) selves; our personal standpoint vanishes (or, which is basically the same, broadens endlessly) until life and death, right and wrong, dream and reality ultimately become "one and the same" again and return to their authentic primordial unity.

What then remains, when the will is abolished, is nothingness (WWR I, 409412). No more thoughts to be thought, no more feelings to be felt, no more emotions to be disturbed by; not even silence, darkness or light - nothing. This is all that is left to those in whom the will has denied itself. Not much, many people will put forward now, and they are probably right. But perhaps Schopenhauer might also be right after all: for those, who are still occupied by their own desires, emotions and interests, who are striving to be happy and successful and desperately long to be loved, and who refuse to let things take their natural course, are surely not better off - for they are not even able to eschew superfluous suffering and unnecessary illusion. ${ }^{1}$

See also 2 Schopenhauer on Scientific Knowledge; 10 Schopenhauer and Platonic Ideas; 17 Schopenhauer on the Metaphysics of Art and Morality; 18 Schopenhauer on the Value of Compassion; 19 Schopenhauer and Indian Philosophy; 20 Life-Denial versus Life-Affirmation: Schopenhauer and Nietzsche on Pessimism and Asceticism; 24 Schopenhauer, Nietzsche, Wagner

\section{References}


Janaway, C. (1996). Knowledge and Tranquillity: Schopenhauer on the Value of Art. In D. Jacquette (Ed.). Schopenhauer, Philosophy, and the Arts (39-61). Cambridge: Cambridge University Press.

Nagel, T. (1986). The View from Nowhere. Oxford: Oxford University Press.

Kant, I. (1987). Critique of Judgment. Including the First Introduction. Translated, with an Introduction by W. S. Pluhar. Cambridge \& Indianapolis: Hackett Publishing Company.

Schopenhauer, A. (1966). The World as Will and Representation. Two vols. Trans. E.F.J. Payne. New York: Dover.

Reginster, B. (2009). Knowledge and Selflessness: Schopenhauer and the Paradox of Reflection. In Neill, A. and Janaway, C. (Eds.). Better Consciousness:

Schopenhauer's Philosophy of Value (99-119). Oxford: Wiley-Blackwell.

Vandenabeele, B. (2003). Schopenhauer, Nietzsche, and the Aesthetically Sublime. Journal of Aesthetic Education, 37, 90-106.

Vandenabeele, B. (2007). Schopenhauer on the Values of Aesthetic Experience.

Southern Journal of Philosophy, 45, 565-582.

Vandenabeele, B. (2008). Schopenhauer on Aesthetic Understanding and the Values of Art. European Journal of Philosophy, 16, 194-210.

Wicks, R. (2008). Schopenhauer. Malden, MA: Blackwell.

Young, J. (1987). The Standpoint of Eternity: Schopenhauer on Art. Kant-Studien, 78, 424-441.

\section{Further Reading}


Diffey, T. (1990). Schopenhauer's Account of Aesthetic Experience. British Journal of Aesthetics, 30, 132-142.

Jacquette, D. (Ed.) (1996). Schopenhauer, Philosophy, and the Arts. Cambridge: Cambridge University Press.

Neill, A. and Janaway, C. (Eds.) (2009). Better Consciousness. Schopenhauer's Philosophy of Value. Oxford: Wiley-Blackwell.

Knox, I. (1980). Schopenhauer's Aesthetic Theory. In Fox, M. (Ed.). Schopenhauer: His Philosophical Achievement (132-146). Brighton: Harvester Press.

Levinson, J. (2006). Schopenhauer's Aesthetics. In Contemplating Art (355-365).

Oxford: Oxford University Press.

Sacks, M. (2000). Objectivity and Insight. Oxford: Clarendon Press.

\footnotetext{
${ }^{1}$ I wish to offer my thanks to Daniel Came, Annelies Monseré, Antoon Van den Braembussche, and Stijn Van Impe for their acute comments to earlier versions. I would also like to thank Hans Maes for inviting me to present a version of this essay at the University of Kent at Canterbury, and the audience for their comments, questions and helpful suggestions.
} 